\title{
(137) FEM tracing toward cracking of steel members under very-low-cycle loading
}

\author{
Yeon-Soo Park, Research Fellow, Disas. Prev. Res. Inst., Kyoto University \\ Satoshi Iwai, Research Associate, Disas. Prev. Res. Inst., Kyoto University \\ Hiroyuki Kameda, Professor, Disas. Prev. Res. Inst., Kyoto University \\ Taijiro Nonaka, Professor, Disas. Prev. Res. Inst., Kyoto University
}

\section{Introduction}

In order to clarify damage and/or failure mechanism of steel members and their elements under severe seismic excitations, a series of the experimental investigations on very-low-cycle loading have been conducted by the authors ${ }^{1-3}$ ). Very-low-cycle loading is meant to involve load repetitions of the order of a few to twenty cycles. The main purpose of numerical analysis is to simulate quantitatively the hysteretic behavior of angle specimens under such loading, especially the local strain history and cumulative state of deformation at their critical parts.

The computer model is based on a three-dimensional, nonlinear hysteretic analysis by using MSC/NASTRAN program which includes the effects of the material and geometric nonlinearities. A total of six specimens selected from the experiments has been simulated in the analysis. Importance of local stress-strain hysteresis under large cyclic excitations is discussed in relation to cracking. All runs have been made on the FUJITSU M-1800/30 computer system of Data Processing Center, Kyoto University.

\section{Outline of experimental study}

The experimental investigations were performed on steel angle members with different loading patterns. Special attention was paid to the inelastic post-buckling behavior of steel members and the state of cumulative plastic strains at the critical part of the specimen. Two types of angles L-40x40x3 and L$40 \times 40 \times 5$ of the SS 400 grade steel served as specimens. Each specimen was pin-supported by holding the end plates, which were attached by welding perpendicularly to the specimen, as indicated in Fig. 1. The effective length $l$, being the tested part between the pin-supports, was $318 \mathrm{~mm}$, as shown in Table 1 .

A slowly varying uni-axial load was applied to near-centroid of the cross-section using a hydraulic servo-actuator with the loading capacity of $294 \mathrm{kN}$. Load was controlled by the relative axial displacement $\Delta$ : The choices of loading pattern were from monotonic elongation ( $\mathrm{M}$ type) and constant displacement amplitude (LC, AC and TC types), as shown in Fig. 2.

In order to measure residual local strain after testing, the dot marking with $2 \mathrm{~mm}$ intervals was made on the surface at the both edges and the corner in the cross-section of the specimen, in the direction parallel to the longitudinal axis for a mid-part length of $80 \mathrm{~mm}$, using a Vickers hardness tester.

Table 1 Specimen sizes and test parameters

\begin{tabular}{|c|c|c|c|c|c|c|c|c|c|c|c|}
\hline \multirow{3}{*}{$\begin{array}{l}\text { Specimen } \\
\text { name }\end{array}$} & \multirow{3}{*}{$\begin{array}{c}\text { Angle } \\
\text { type }\end{array}$} & \multirow{3}{*}{$\begin{array}{l}\text { Length } \\
l(\mathrm{~mm})\end{array}$} & \multirow{3}{*}{$\begin{array}{l}\text { Width } \\
b(\mathrm{~mm})\end{array}$} & \multirow{3}{*}{$\begin{array}{c}\text { Thickness } \\
t(\mathrm{~mm})\end{array}$} & \multirow{3}{*}{$\begin{array}{l}\text { Loading } \\
\text { pattern }\end{array}$} & \multicolumn{4}{|c|}{ Number of load cycles } & \multicolumn{2}{|c|}{ train at cracked part } \\
\hline & & & & & & Crack & Crack & Crack & Rupture & Tens. & Comp. \\
\hline & & & & & & 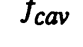 & $t_{v}$ & $t_{n}$ & $f_{m}$ & $\varepsilon_{\text {tens }}$ & $\varepsilon_{\text {comp }}$ \\
\hline T3M & $\mathrm{L}-40 \times 40 \times 3$ & 316 & 39.7 & 2.97 & $\mathbf{M}$ & -- & - & -- & -- & $115 \%$ & -- \\
\hline L3CP & $\mathrm{L}-40 \times 40 \times 3$ & 318 & 39.6 & 2.83 & LC & 5 & 8 & 8 & 23 & $30 \%$ & $-32.5 \%$ \\
\hline $\mathrm{A} 3 \mathrm{CP}$ & $\mathrm{L}-40 \times 40 \times 3$ & 316 & 39.7 & 2.99 & $\mathrm{AC}$ & 4 & 7 & 8 & 17 & $35 \%$ & $-30 \%$ \\
\hline T3CP & L- $40 \times 40 \times 3$ & 316 & 39.7 & 2.97 & TC & 4 & 8 & 8 & 17 & $35 \%$ & $-30 \%$ \\
\hline
\end{tabular}

[Note] $f_{\text {cav }}$ : Number of cycles to first cracking on the concave side of bending deformation, $f_{\text {vex }}:$ Number of cycles to first cracking on the convex side of bending deformation, $f_{p e n}$ : Number of cycles to penetration in direction of plate thickness, $f_{\text {rup }}$ : Number of cycles to rupture, $\varepsilon_{\text {tens }}:$ Maximum absolute values of residual "net" strain at cracked part of elongation side, $\varepsilon_{\text {comp }}:$ Maximum absolute values of residual "net" strain at cracked part of contraction side 


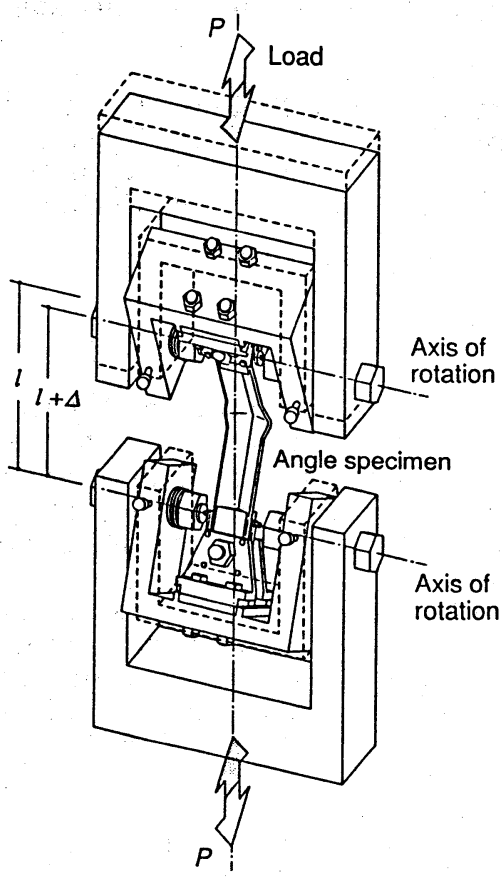

Fig. 1 Specimen supporting system.

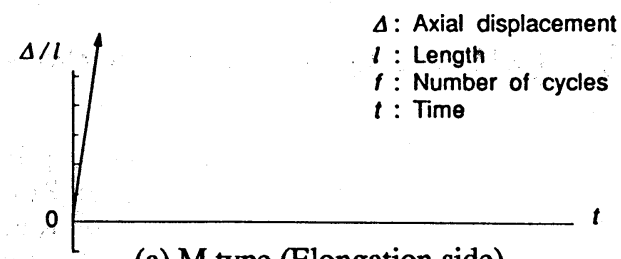

(a) M type (Elongation side)

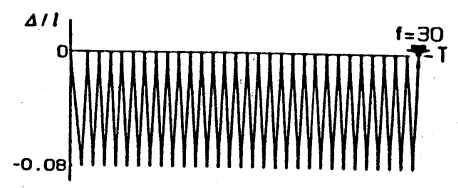

(b) LC type (Contraction side)

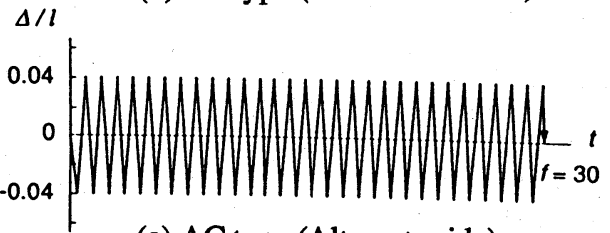

(c) AC type (Alternate side)

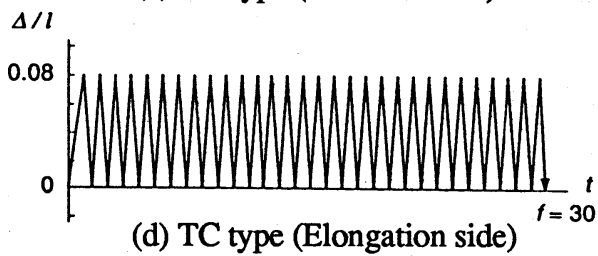

Fig. 2 Loading patterns.

\section{Experimental results}

Fig. 3 is a sketch of buckling deformation and visible cracking. During testing, the positive (P mode) and negative ( $\mathrm{N}$ mode) deflections were observed as defined in the figure. The global buckling deflection was accompanied by significant localized deformation due to plate buckling of the leg at the mid-part of the specimen, which induced very large strains. Typical examples of the observed load-axial displacement relationships are shown in Fig. 4. Here the load $P$ and relative displacement $\Delta$ are normalized by the yield load $N_{y}$ and length $l$, respectively.

The number of load cycles at three cracking states and rupture are shown for each specimens in Table 1 . Irrespective of the loading patterns and deflection modes, visible cracks were initiated during stretching on the concave side of the overall buckling deformation induced in the preceding load cycles. Visible cracks at the convex side were observed within 1-4 cycles following the concave side cracking. Cracking on the concave and convex sides rapidly penetrated through the thickness of the legs. Visible cracks was located near the regions of severe concentration of strains.

The maximum absolute value of residual "net" strains at the outbreak of a visible crack under very-lowcycle loading was of the order of $30-35 \%$ (see $\varepsilon_{\text {tens }}$ and $\varepsilon_{\text {comp }}$ in Table 1), independent of the test parameters. However, under the monotonic-tensile tests with T3M specimen (Table 1) and JIS (Japanese Industrial Standard) material specimen ${ }^{1,2)}$, the maximum "net" local strain near the ruptured portion was about $100 \%$. The residual strain values in the very-low-cycle experiments are considered to reflect the effect of repeated loading.

\section{FEM modeling and loading}

A typical finite element model for the angle specimen is shown in Fig. 5. The 4-noded quadrilateral isoparametric shell elements (QUAD4 elements) were used in modeling the tested angle specimen. The material property in this analysis has been assumed to be bilinearly etasto-plastic with kinematic hardening. The yield stress $\sigma_{y}$, Young's modulus $E_{s}$ and Poisson's ratio $v$ were taken to be $349 \mathrm{~N} / \mathrm{mm}^{2}, 2.06 \times 10^{5}$ 
$\mathrm{N} / \mathrm{mm}^{2}$ and 0.3 , respectively. The slope $E_{t}$, in the strain hardening region, of the stress-strain curve was selected at $1 \%$ of $E_{s}$. The von Mises yield criterion was used.

Both ends of the specimen were simply supported. Both end-holding blocks of the test specimen (see Fig. 1) were modeled by using the 3-noded stiff shell elements and the stiff QUAD4 elements for providing rigid-body motion in the vicinity of ends. The model had 306 shell elements as described in Fig. 5. A total of 1628 degrees of freedom was used in this analysis. As for the degrees of freedom, only the in-plane rotation was constrained in all the nodes of each shell elements.

The analyzed models were subjected to cyclic enforced axial displacement, in the contraction side (L3CP model), alternate side (A3CP model) and elongation side (T3CP model) with a constant amplitude $8 \%$ of the length $l$. In order to produce a desired deflection mode shown in Fig. 6, the load was applied with small eccentricities distant from the centroid of each end cross-section in the Z-direction (Fig. 5), similarly to the experiment. The given eccentricity was $-0.2 \mathrm{~mm}$ ( $\mathrm{A} 3 \mathrm{CP}$ model), $-0.5 \mathrm{~mm}$ ( $\mathrm{L} 3 \mathrm{CP}$ model) and $1.0 \mathrm{~mm}$ (T3CP model). The analysis was basically performed up to the number of cycles where outbreak and/or penetration of cracks through the thickness of the angle leg were observed in the experiment. The analysis for each model took about 3 hours of CPU time on the average.

\section{Load-axial disolacement relations}

A comparison is made in Figs. 4 and 7 for typical load-axial displacement curves from the experiment and analysis. The analytical overall behaviors show good agreement with the experimental results. In the case of loading started from the contraction side (see (a) in Figs. 4 and 7), the compressive load decreased suddenly after the global buckling occurred at an early stage of the first cycle accompanied with the inelastic local buckling. Here one cycle is defined with reference to the load $P$, starting at zero, undergoing load reversal and returning to zero.

The compressive load-carrying capacities at each cycle after the first cycle were significantly reduced, but only a small decrease was seen in the succeeding tensile load-carrying capacities. A fairly higher compressive strength in the second cycle under the alternately constant displacement loading (A3CP model) was calculated by the numerical analysis, as indicated in Fig.7(b). This phenomenon may be attributed to the compressive loading for the nearly straight model regained by purely tensile yielding after being

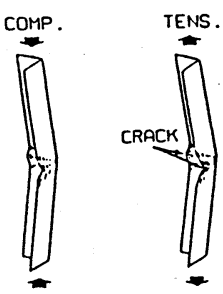

(a) P mode

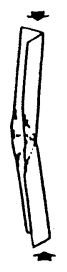

(b) $\mathrm{N}$ mode

Fig. 3 Deflection modes

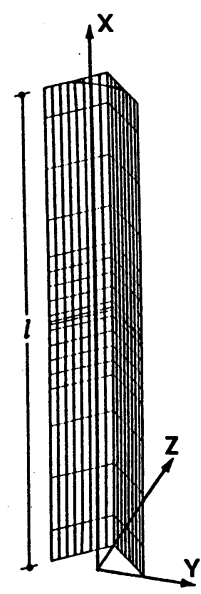

Fig. 5 Typical model.

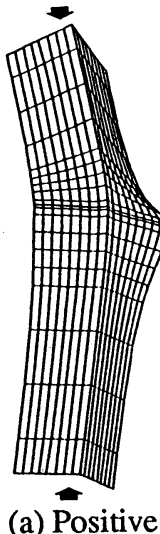

mode

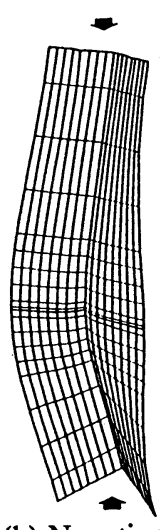

(b) Negative mode

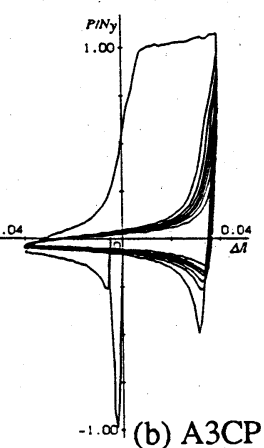

(b) $\mathrm{A} 3 \mathrm{CP}$

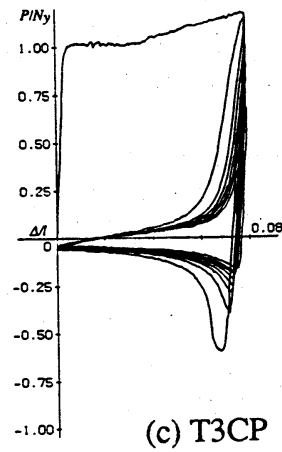

(c) $\mathrm{T} 3 \mathrm{CP}$

(a) $\mathrm{L} 3 \mathrm{CP}$

Fig. 4 Load-axial displacement relations [Experiment].
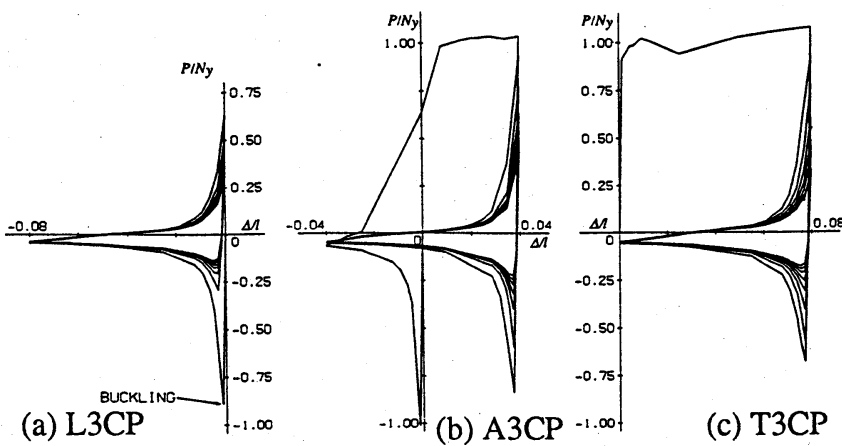

Fig. 7 Load-axial displacement relations [Analysis]. 


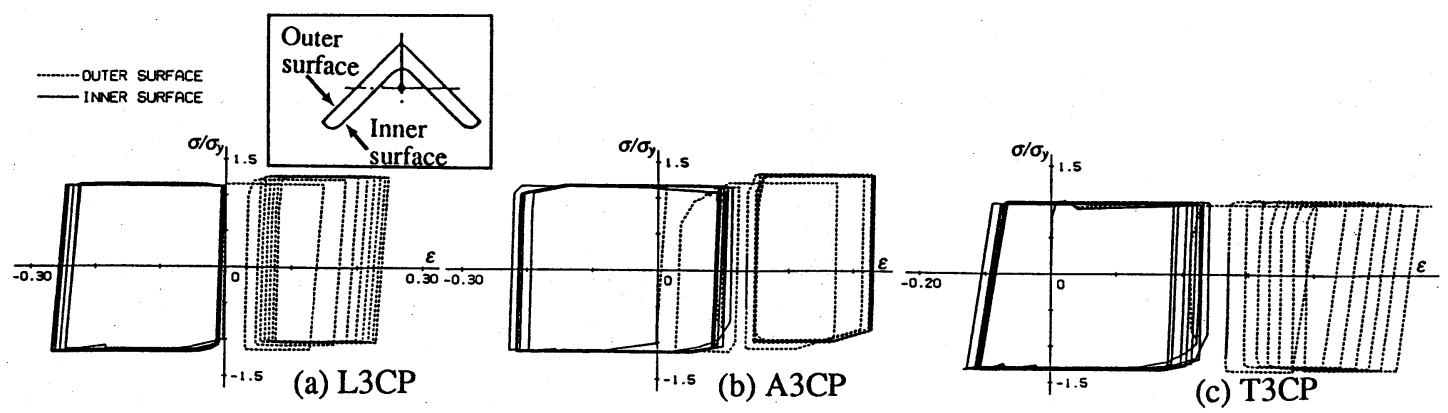

Fig. 8 Local stress-strain hysteresis [Analysis].
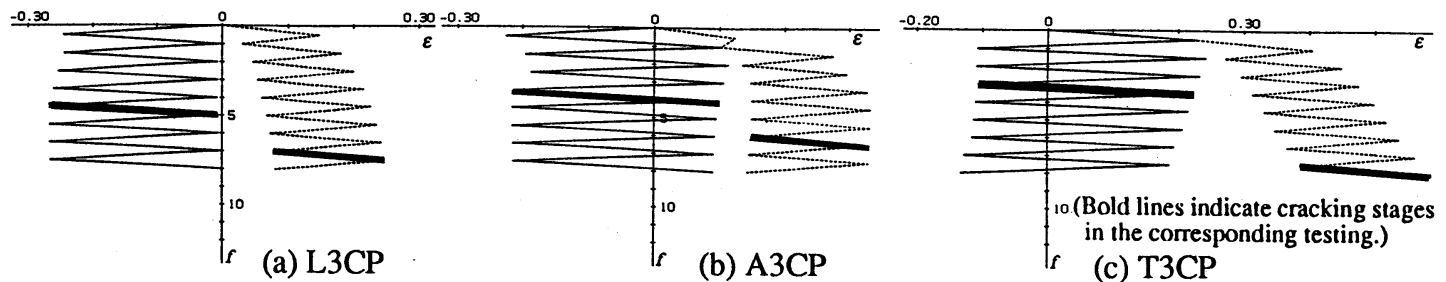

Fig. 9 Local strain histories with the increasing number of cycles [Analysis].

plastically deformed into a crooked configuration. In the case of loading started from the elongation side (Fig. 7(c)), the compressive strength in the first cycle was reduced considerably by the plastic crookedness due to the eccentric tensile loading.

\section{Simulation of local strain history}

Figs. 8 and 9 show the axial stress-strain hysteresis and the plastic local strain history, respectively, on the inner and outer surfaces of the edge element of the mid-height cross-section. The amplitudes, i. e. the variable widths, of local strain on the inner surface of the critical elements were ranged approximately 11.8$33.6 \%$ in the first cycle. This indicates that the angle model under the very-low-cycle loading have partially experienced very large strain with inelastic local deformation.

A small change of the amplitudes of strain variation per each cycle was observed. Regardless of the loading patterns, the strain amplitude on the inner surface is larger than that on the outer surface. Therefore, the most severe concentration of local deformation occurs at the inner surface of the edge element of the mid-height portion. This seems to be the experimental phenomenon that the first cracking was observed on the concave side of the overall buckling deformation.

A trial computation was made for the summation of plastic components of strain in the tensile stress side in each cycle, up to the outbreak of cracks indicated by bold lines in Fig. 9. This attained the values of $104-255 \%$, irrespective of the loading patterns. These figures correspond to the residual local strain of 90 $115 \%$ at the ruptured portion under the monotonic-tensile loading with the T3M and JIS material specimen. This sum might be an indicator to represent the accumulated damage due to very low-cycle loading.

\section{Conclusions}

The results of numerical analysis by the FEM program were presented for steel angle members under very low-cycles of loading. The overall behavior from the analysis showed good agreement with the experiment. The local strain history at the critical section was traced for large cyclic deformation by the numerical analysis. Under the very-low-cycles of loading, the angle model has partially experienced very large strain involving inelastic local deformation. The most severe strain-cycling occurred on the concave surface of the overall buckling deformation. It is possible that the local strain information in relation to cracking might be used to evaluate the seismic damage for steel members and their elements.

References 1) S. Iwai, Y.-S. Park, T. Nonaka and H. Kameda: Very Low-Cycle Fatigue Tests of Steel Angle Members under Earthquake Loading, Proc. of 10th World Conference on Earthquake Engineering, Madrid, Vol. 5, pp. 2879-2884, 1992. 2) S. Iwai, Y.-S. Park, T. Nonaka and H. Kameda: Very LowCycle Fatigue Tests of Steel Angles, Jour. of Structural and Construction Engineering, Architectural Institute of Japan, No. 445, pp. 139-149, 1993 (in Japanese). 3) S. Iwai, T. Nonaka, Y.-S. Park and H. Kameda: Experimental Observation on Fatigue of Steel Members and Elements under Very Low LoadCycles, Proc. of 2 nd European Conference on Structural Dynamics, Trondheim, Norway, June. 1993. 